\title{
IMPLANTAÇÃO E MONITORAMENTO DE UM PROGRAMA DE EDUCAÇÃO AMBIENTAL PARA O DESCARTE CORRETO DE BITUCAS DE CIGARRO
}

\author{
Alexandre Nascimento de Almeida ${ }^{1}$ \\ Loyane Soares Neves ${ }^{2}$ \\ Andréa de Oliveira Gonçalves ${ }^{3}$ \\ Humberto Angelo ${ }^{4}$ \\ Elisangela Lobo Schirigatti ${ }^{5}$
}

Resumo: O objetivo do trabalho é criar, aplicar e avaliar um programa de educação ambiental na Universidade de Brasília, campus de Planaltina (FUP). O programa desenvolveu um trabalho de conscientização sobre os males das bitucas de cigarro para o meio ambiente, bem como, instalou e distribuiu equipamentos para o recolhimento adequado das bitucas. $\mathrm{O}$ monitoramento ocorreu por meio da coleta e comparação do volume de bitucas descartados incorretamente antes e depois do programa de educação ambiental por meio do teste não paramétrico de Mann-Whitney. Os resultados indicaram que o volume de bitucas descartados no chão reduziu em cerca de quatro vezes após a aplicação do programa, indicando que o publico envolvido não apresentou resistência na sua mudança de comportamento.

Palavras-chave: Educação Ambiental; Gestão Ambiental; Bitucas de Cigarro.

\footnotetext{
${ }^{1}$ Faculdade UnB de Planaltina. E-mail: alexalmeida@unb.br

${ }^{2}$ Faculdade UnB de Planaltina. E-mail: loyanesoares@gmail.com

${ }^{3}$ Faculdade UnB de Planaltina. E-mail: andreagon@unb.br

${ }^{4}$ Universidade de Brasília. E-mail: humb@unb.br

${ }^{5}$ Universidade Tecnológica Federal do Paraná. E-mail: elisangelal@utfpr.edu.br

Revbea, São Paulo, V. 10, N 1: 42-55, 2015.
} 


\section{Introdução}

A crise ambiental se torna cada vez mais evidente, principalmente em função da intensificação dos impactos ambientais das atividades humanas. Nesse contexto, a necessidade de introduzir na educação dos cidadãos princípios básicos de ecologia e de conservação dos recursos naturais levou ao surgimento da educação ambiental (LAYRARGUES, 2003).

Para falar em educação ambiental, necessariamente devemos falar de atitudes, de cultura, de qualidade de vida, de respeito, de ética, de cidadania, de sociedade, de natureza, de recursos naturais, de água, de energia, de ar, de terra, enfim, poderíamos continuar por um bom tempo listando a abrangência do assunto "educação ambiental" (ADAMS, 2006).

Uma vertente da educação ambiental, relativamente pouco trabalhada, porém, com grandes implicações no meio ambiente, é a problemática referente ao descarte incorreto de bitucas de cigarro. Conforme o Instituto Nacional de Câncer - INCA (1996), a bituca de cigarro é considerada o lixo mais comum do mundo, representando cerca de $30 \%$ de lixo de mão jogado nas ruas, bueiros, praias e é um resíduo totalmente tóxico.

A difusão da educação ambiental demanda profissionais preparados para lidar com sua complexidade, pois, além de abrangente, demanda um caráter interdisciplinar. A evidência dessa interdisciplinaridade é facilmente visualizada pelo envolvimento de questões relacionadas à saúde e ao meio ambiente, ambas relacionadas aos males do cigarro. Nunca é demais lembrar que o cigarro mata cinco milhões de pessoas anualmente no mundo, no Brasil são 200 mil mortes anuais. É mais do que a soma das mortes por alcoolismo, AIDS, acidentes de trânsito, homicídios e suicídios juntos (INCA, 2007).

A educação ambiental, em uma perspectiva conservadora, tem como principal objetivo a mudança comportamental do indivíduo. Do modo pelo qual o sujeito se firma no mundo, modificando a realidade objetiva e sendo modificado de forma reflexiva pelo autoquestionamento, remetendo teoria à prática (LOUREIRO, 2004). No entanto, avaliar essa transformação comportamental é que torna o grande desafio desse trabalho e de qualquer pesquisa que aborde a educação ambiental.

A avaliação da eficiência da educação ambiental é um tema considerado muito complexo na opinião da maioria dos autores que se dedicam ao tema. Segundo Layrargues (2000) a avaliação da educação ambiental tem se mostrado uma das principais lacunas que prejudicam o avanço do campo. Seja pela inadequação dos instrumentos avaliativos tradicionais ou pela ausência de instrumentos específicos, a avaliação de ações de educação ambiental tem se configurado como uma questão problemática nos últimos anos (TOMAZELLO; FERREIRA, 2001). É evidente a escassez de trabalhos que tratem especificamente sobre o tema, o que demonstra que a discussão se encontra em um estágio imaturo de desenvolvimento. A relevância de tal avaliação é oficialmente reconhecida, mas é parco orientações sobre sua execução. 
Esse trabalho tem como objetivo criar, aplicar e avaliar um programa de educação ambiental na Universidade de Brasília, campus de Planaltina (FUP - Faculdade UnB de Planaltina). Nesse sentido traçaram-se os seguintes objetivos específicos:

1) Estruturar um programa de educação ambiental, contendo objetivos e delimitando as atividades.

2) Avaliar o efeito do programa de educação ambiental na mudança de comportamento dos envolvidos no processo.

\section{Material e Métodos}

\section{Atividades do Programa de Educação Ambiental}

O projeto de implantação do programa de educação ambiental é voltado para a conscientização e coleta de bitucas de cigarro no campus da FUP. Foram instalados caixas coletoras específicas para as bitucas de cigarro e distribuído porta bitucas portáteis para os fumantes do campus. Além da instalação e distribuição de equipamentos, o programa ressaltou a importância de mudança de hábitos dos fumantes para que estabelecessem um compromisso de responsabilidade individual referente à conservação do meio ambiente. Portanto, além de propiciar uma infraestrutura, criando um ambiente propício e adequado para o descarte das bitucas de cigarro, o projeto desenvolveu um trabalho de conscientização sobre os males das bitucas no meio ambiente por meio da difusão de informação via cartazes, mensagens eletrônicas e interpessoais por meio das seguintes atividades:

Atividade 1: Criação de uma fanpage na rede social

Objetivo: Divulgar informação e passar conhecimento para o público virtual

Metodologia: Por meio da rede social foi possível difundir e discutir ideias, entrando em um processo de aquisição ou reconstrução de valores e conceitos relacionados à bituca de cigarro. Neste veículo de informação foram organizadas notícias pertinentes sobre as bitucas de cigarro e seus impactos, bem como, divulgado o cronograma de todas as atividades do projeto. Semanalmente foram publicados os cartazes educativos, vídeos, mantendo as informações sempre atualizadas e possibilitando um feedback imediato dos participantes (Figura 1).

Atividade 2: Elaboração de cartazes educativos

Objetivo: Mostrar ao público do campus dados e curiosidades sobre as bitucas de cigarro

Metodologia: Os cartazes levaram consigo a vontade de transmitir e o desejo de ser eficaz, tornando um grande mecanismo de comunicação em massa. A partir da percepção do conhecimento do público respondente, elaboraram-se

Revbea, São Paulo, V. 10, Nº 1: 42-55, 2015. 
frases com intuito de levar informações, até então, desconhecidas pelo público alvo ou que se passava despercebida (Figura 2). Foram produzidos 17 cartazes, sendo espalhados em diversos locais da FUP onde as pessoas tivessem a maior facilidade de leitura.

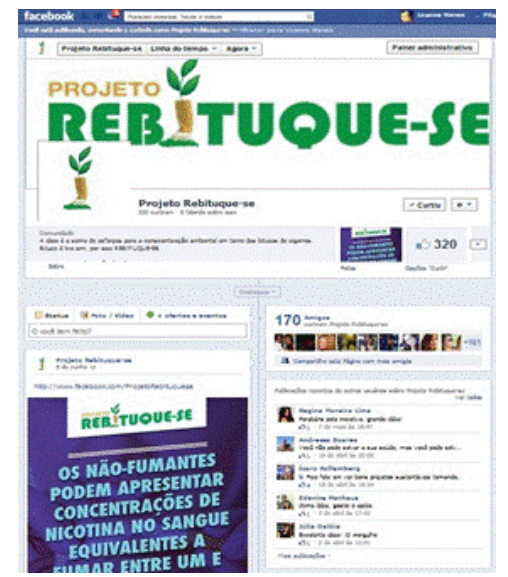

Figura 1: Fanpage do Projeto Rebituque-se.

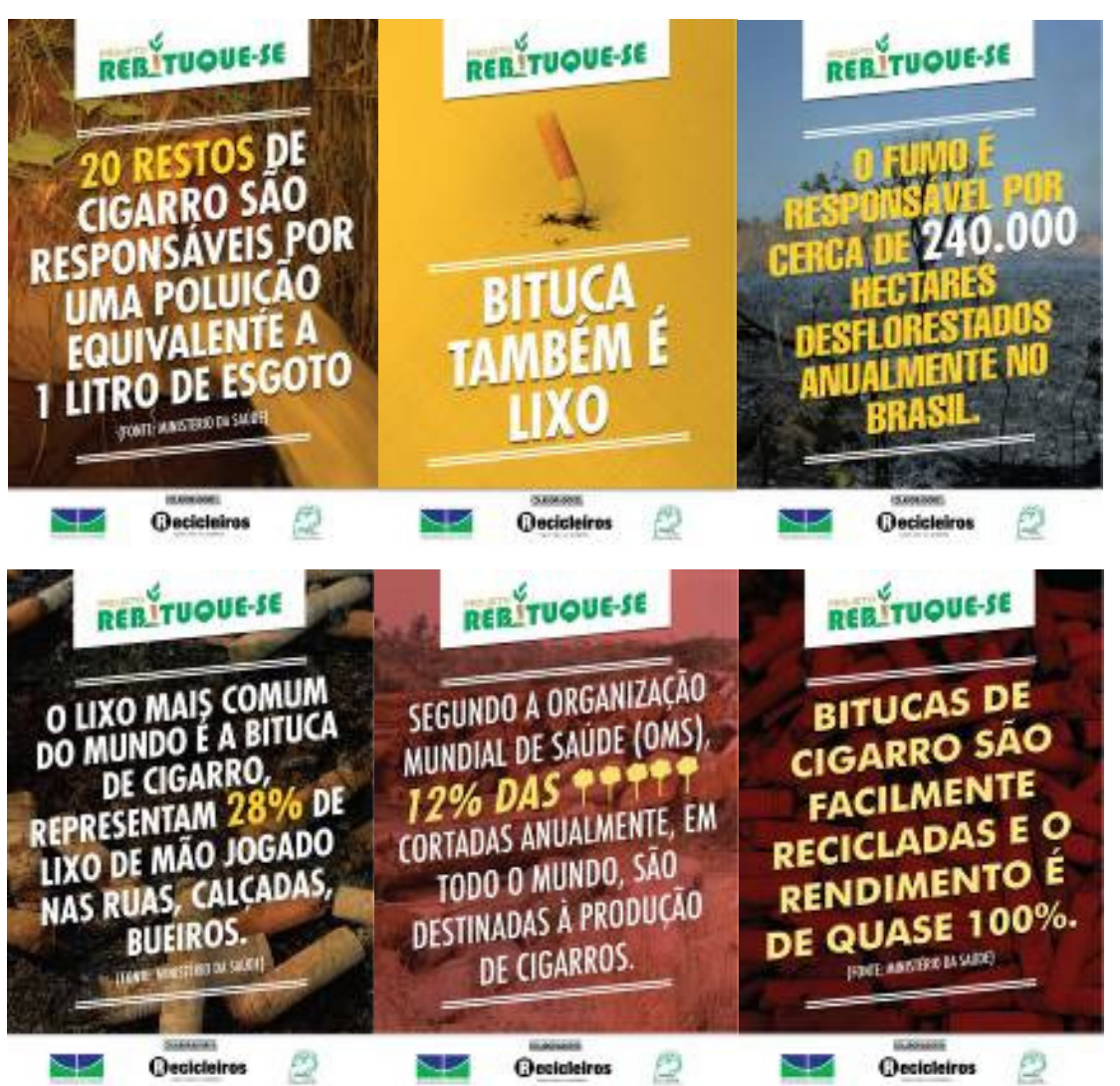

Figura 2: Exemplos de cartazes educativos utilizados 
Atividade 3: Instalação das caixas coletoras de bitucas de cigarro

Objetivo: Coletar as bitucas de cigarro

Metodologia: Foram instaladas quatro caixas coletoras pelo campus da FUP. O local escolhido para instalação das caixas coletoras se deu a partir de mapeamento dos locais onde havia mais bitucas concentradas no chão. Com essa percepção, instalaram-se as caixas coletoras nesses locais, facilitando a utilização das mesmas pelos fumantes. Nessas caixas coletoras, teve-se a opção de colocar cartazes educativos, sendo outro meio de comunicação com os fumantes e os que não fumam (Figura 3).

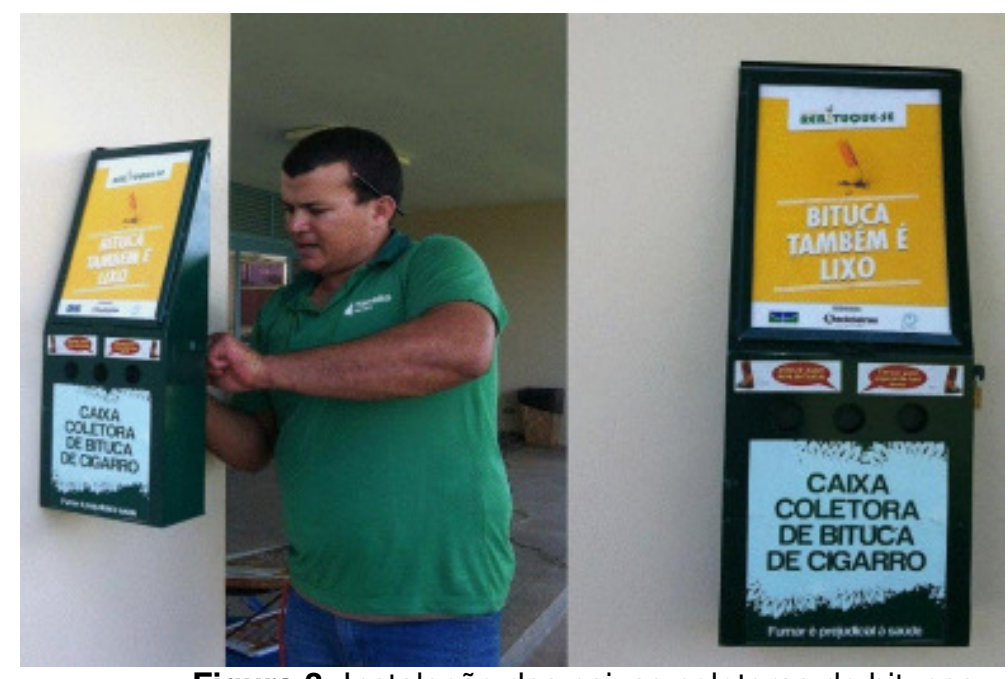

Figura 3: Instalação das caixas coletoras de bitucas

Atividade 4: Distribuição dos porta bitucas portáteis

Objetivo: Diminuir a incidência de bitucas espalhas pelo chão do campus

Metodologia: Distribuíram-se porta bitucas portáteis para os fumantes do campus. A distribuição para os alunos e professores ocorreu diretamente em sala de aula, aproveitando o momento para divulgar o projeto e suas ações, utilizando panfletos educativos para contribuir na comunicação (Figura 4). A distribuição dos porta bitucas para os funcionários fumantes foi pessoalmente. Instruiu-se que após o porta bituca estiver cheio (capacidade de 30 bitucas), as mesmas deveriam ser dispensadas nas caixas coletoras. Foram distribuídos 200 porta bitucas (Figura 5).

Atividade 5: Colocação de cartazes do Ministério da Saúde

Objetivo: Informar sobre os malefícios causados pelo fumo

Metodologia: O cigarro ou qualquer outro derivado do tabaco jamais poderá ser considerado um produto seguro para o consumo, dessa forma, levar a informação sobre o risco de fumar se torna fundamental no projeto, contribuindo para reforçar a imagem negativa do cigarro nas suas diferentes Revbea, São Paulo, V. 10, Nº 1: 42-55, 2015. 
dimensões. Por meio de auxílio do Ministério da Saúde no fornecimento de 50 cartazes, divulgaram-se os malefícios do cigarro para saúde dos seus usuários pelo campus (Figura 6).

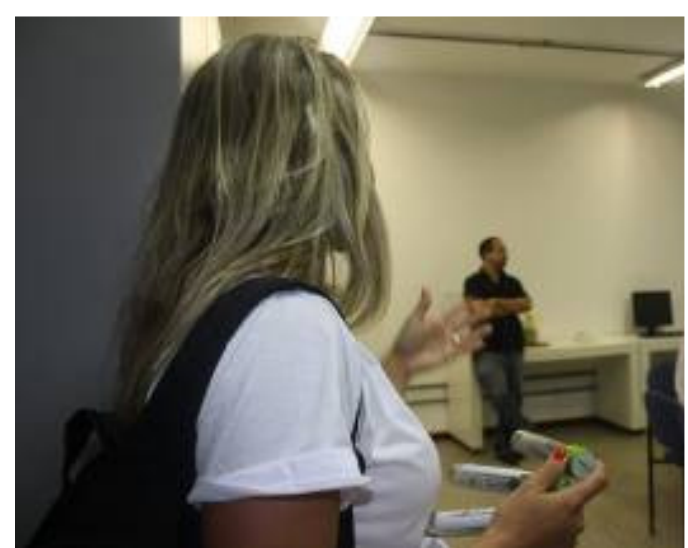

Figura 4: Distribuição dos porta bitucas portáteis

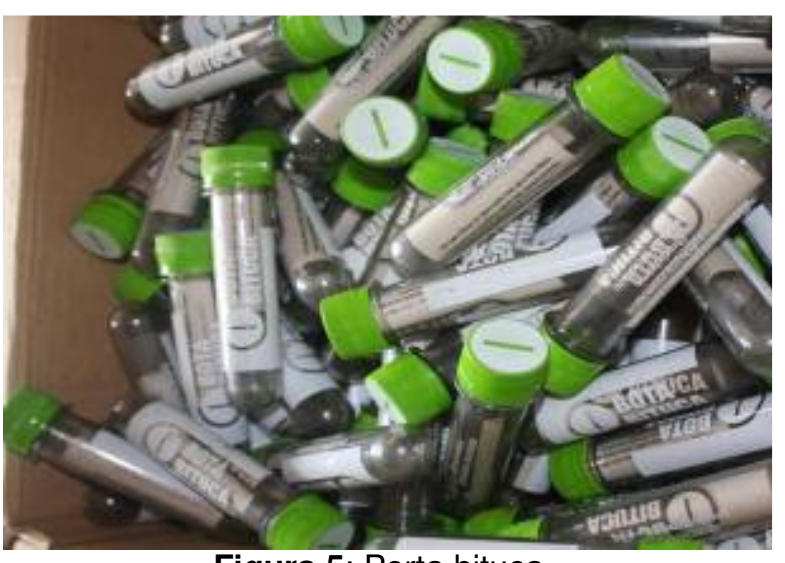

Figura 5: Porta bituca

Figura 6: Cartaz fornecido pelo Ministério da Saúde

\section{Monitoramento do Programa de Educação Ambiental}

Como bem apresentado por Pedrini et al. (2012), existem diferentes formas de avaliar a educação ambiental, quanto à etapa temporal temos situações ex ante, on going ou ex post; quanto aos métodos de aplicação, pode ser formal (SOARES, 2005) ou não-formal (VIEIRA et al., 2003); pode utilizar a analise de conceitos-chaves (CHOU \& ROTH, 1995) ou contextos específicos expressos em depoimentos orais (TABANEZ et al., 1997), a avaliação pode ser feita na prática por meio do monitoramento de indicadores de desempenho (BUTZKE et al., 2001) ou por questionários impressos (TRAJBER \& COSTA, 2001); podendo ocorrer no ambiente escolar, comunitário ou empresarial como demonstrou Azevedo (2003). 
Similar a Butzke et al. (2011), o monitoramento da eficiência do programa de educação ambiental ocorreu por meio do recolhimento e comparação do volume de bitucas descartados incorretamente antes e depois do programa implementado, permitindo verificar pelo indicador escolhido (volume de bitucas descartadas incorretamente) se o conhecimento transmitido pelo programa foi assimilado e, principalmente, se foi transformado em ação efetiva.

A coleta das bitucas foram feitas manualmente por todo o campus da FUP. Primeiramente limpou-se toda a área e, durante quatro dias consecutivos, coletaram-se todas as bitucas descartadas incorretamente, repetindo 0 processo durante cerca de dois meses antes e dois meses depois do programa de educação ambiental (Tabela 1). Para facilitar a comparação dos dados, após coletadas, as bitucas foram secas e pesadas.

Tabela 1: Cronograma de todas as atividades desenvolvidas.

\begin{tabular}{|c|c|c|c|c|c|c|}
\hline & & & 2013 & & & \\
\hline & Janeiro $^{2}$ & Fevereiro $^{2}$ & Março & Abril & Maio & Junho \\
\hline $\begin{array}{l}\text { Recolhimento das } \\
\text { Bitucas }\end{array}$ & $X$ & $X$ & $X$ & & & \\
\hline $\begin{array}{c}\text { Programa de } \\
\text { Educação Ambiental }^{1}\end{array}$ & & & & $\mathrm{X}$ & & \\
\hline $\begin{array}{c}\text { Novo Recolhimento } \\
\text { das Bitucas }\end{array}$ & & & & & $X$ & $X$ \\
\hline
\end{tabular}

Fonte: Elaboração dos autores

Notas: ${ }^{1}$ Embora a abordagem direta tenha ocorrido no mês de abril, os cartazes do programa de educação ambiental permaneceram fixados nos meses de maio e junho.

2 Durante o ano de 2013, devido a greve dos professores em 2012, ocorreram atividades acadêmicas de reposição nos meses de janeiro e fevereiro.

A amostra do recolhimento de bitucas no campus contou com 12 casos antes e 11 casos depois do programa aplicado. Devido ao pequeno tamanho da amostra e seguindo as orientações de Pestana e Gageiro (2005), optou-se pela aplicação do teste não paramétrico de Mann-Whitney para avaliação estatística da eficiência do programa, partindo da seguinte hipótese:

H0: O descarte incorreto de bitucas não variou após o programa de educação ambiental.

H1: O descarte de bitucas no chão reduziu após o programa de educação ambiental.

Muitos softwares estatísticos calculam o teste de Mann-Whitney, tratase de um teste relativamente simples e que, conforme Hoffmann (2006) pode ser descrito em três etapas: 


\section{1․ Etapa}

São reunidas duas amostras e atribuído a cada uma das observações um número de ordem ou posto, de um a $\mathrm{N}$, que corresponderia à posição ocupada pela observação em uma sequência ordenada de acordo com o valor crescente das observações. Se verificarmos que, considerando as duas amostras, existem duas ou mais observações com valores iguais são atribuídos a cada uma delas a média aritmética dos postos ocupados pelas observações iguais.

\section{2을 Etapa}

Após a ordenação dos valores, pode-se obter a estatística do teste de Mann-Whitney pela escolha do menor valor de $U$ calculado pelas equações [1] e [2].

$$
\begin{gathered}
\mathrm{U}_{1}=\mathrm{n}_{1} \mathrm{n}_{2}+\frac{\mathrm{n}_{1}\left(\mathrm{n}_{1}+1\right)}{2}-\mathrm{R}_{1}[1] \\
\mathrm{U}_{2}=\mathrm{n}_{1} \mathrm{n}_{2}-\mathrm{U}_{1}[2]
\end{gathered}
$$

Em que:

$\mathrm{n}_{1}=$ dimensão da menor amostra

$\mathrm{n}_{2}=$ dimensão da maior amostra

$\mathrm{R}_{1}=$ soma das ordenações da menor amostra

\section{3ำ Etapa}

Uma vez que $U$ é uma variável discreta, utiliza-se uma aproximação à normal nos casos de $n_{1} \geq 10, n_{2} \geq 10$, ou de $n_{1}$ igual a 3 ou 4 e $n_{2}>12$, sendo a expressão do teste dada pela equação [3].

$$
Z=\frac{U-\frac{n_{1} n_{2}}{2}}{\sigma_{U}} \cap N(0 ; 1)[3]
$$

Quando ocorrem empates envolvendo elementos dos dois grupos e a dimensão dos empates não é pequena, a expressão do desvio padrão é dada pela equação [4], para todas as outras situações, a expressão do desvio padrão é dado pela equação [5].

$$
\sigma_{u}=\sqrt{\frac{n_{1} n_{2}}{n(n-1)}\left(\frac{n^{3}-n}{12}-\sum_{j} \frac{t_{j}^{3}-t_{j}}{12}\right)}[4]
$$

Em que:

$\mathrm{t}_{\mathrm{j}}=$ número de observações empatadas em cada grupo $\mathrm{j}$

$$
\sigma_{u}=\sqrt{\frac{n_{1} n_{2}(n+1)}{12}}[5]
$$


Depois de calculado o valor de Z, este é comparado com o valor tabelado de uma distribuição normal para um teste bicaudal, o nível de significância admitido foi de $10 \%$.

Se o valor de $Z$ estiver dentro da região de aceitação do teste, concluise que não existe diferença entre os grupos analisados (aceita $\mathrm{H} 0$ ), caso contrário, os grupos são estatisticamente diferentes (rejeita H0), ou seja, o programa de educação ambiental foi eficiente.

\section{Resultados e Discussões}

O efeito do programa de educação ambiental no comportamento da comunidade da FUP mostrou-se extremamente contundente, o volume de bitucas descartados no chão reduziu em cerca de quatro vezes após a aplicação do mesmo.

Dado a discrepância dos resultados antes e depois do programa de educação ambiental (Figura 7), a realização da análise estatística, nesse caso, tornou-se previsível. O teste de Mann-Whitney rejeitou H0 ao nível de $1 \%$, indicando que o descarte incorreto das bitucas diminuiu drasticamente imediatamente após o programa de educação ambiental.

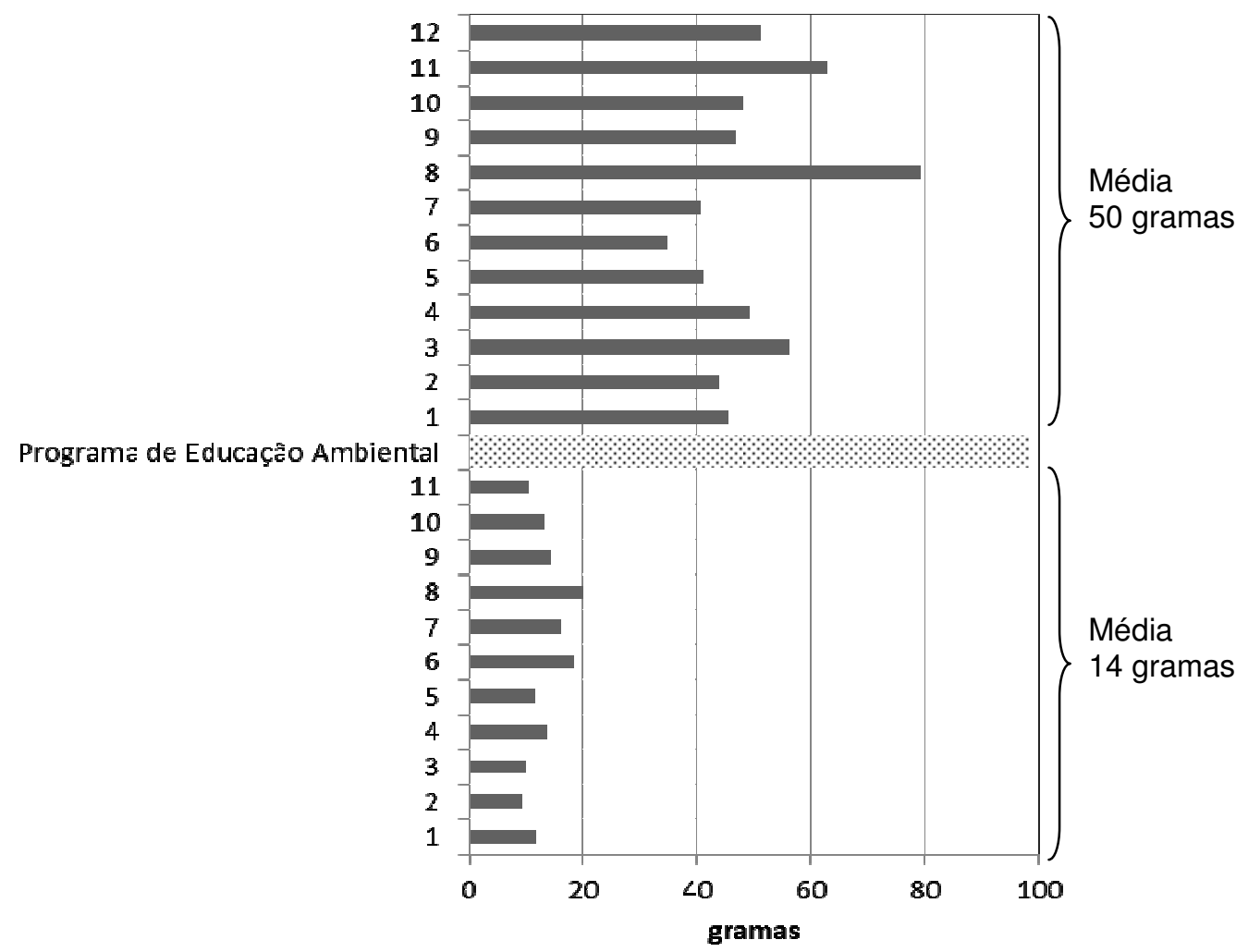

Figura 7: Efeito do programa de educação ambiental no descarte das bitucas

Revbea, São Paulo, V. 10, Nº 1: 42-55, 2015. 
Embora o programa aplicado tenha sido relativamente modesto e rápido (duração de um mês), os bons resultados podem ser explicados por três motivos:

- Disponibilidade dos envolvidos: em sua maioria, o público envolvido é composto de jovens e com um nível de educação acima da média, portanto, menos resistentes a mudanças de comportamento o que, certamente, facilitou a persuasão dos mesmos. Além disso, a mudança de comportamento desejado (descarte correto das bitucas) é de fácil adoção pelos envolvidos, principalmente, após a instalação das caixas coletoras e distribuição dos porta bituca portáteis. Contribuindo para explicar os resultados positivos, Dias (2009: p.115) apontou:

A educação ambiental é mais eficiente na mudança de comportamento comparativamente ao marketing ambiental e a legislação quando o público alvo está propenso a se comportar como os elaboradores das políticas desejam ou quando as externalidades são baixas.

- Ligação dos envolvidos com o meio ambiente: a FUP, campus onde foi realizado o projeto, é voltada para cursos onde a temática ambiental é constantemente trabalhada: Gestão Ambiental, Ciências Naturais, Gestão do Agronegócio e Educação do Campo. Portanto, em geral, o público trabalhado possui, além de um maior conhecimento ambiental, uma maior ligação emocional com a natureza, permitindo que uma simples exposição do tema, mesmo que em um período curto, seja suficiente para as pessoas mudarem de comportamento. Chan e Lau (2000) indicaram que uma ligação emocional com o meio ambiente é mais importante que o conhecimento das relações ecológicas na explicação do comportamento ambiental das pessoas. Por outro lado, Straughan e Roberts (1999), são da opinião que o comportamento do consumidor irá variar consoante o seu nível individual de conhecimento ambiental. Ou seja, tanto na concepção de Chan e Lau (2000) quanto na de Straughan e Roberts (1999), o publico trabalhado encontrou-se mais propício para uma mudança de comportamento.

- Monitoramento no curto prazo e logo após a implantação do programa: possivelmente, o efeito do programa deve reduzir no longo prazo, à medida que a comunidade da FUP se modifique e as mensagens comunicadas tornemse menos latente. Não foi objetivo de a pesquisa analisar o efeito de longo prazo do programa aplicado, porém, sugere-se uma reaplicação ou reforço constante do mesmo, bem como, a manutenção dos monitoramentos em intervalo de tempo definido. Santos e Da Silva (2011) concluíram que o objetivo de transformação da educação ambiental está sendo obtido de modo tímido, em função, principalmente, da falta de continuidade dos projetos. 
Os resultados da pesquisa estiveram alinhados com os encontrados por Afonso (2009), que verificou a relação entre a intenção de uma atitude ambientalmente correta com a efetiva ação em favor do meio ambiente.

O monitoramento do projeto, apesar das conclusões de Mattos e Loureiro (2001), Depresbiteris (2001) e Tomazello e Ferreira (2001), são suficientes para auxiliar a tomada de decisão e melhorar o programa aplicado. Segundo os autores supracitados, as formas de avaliação tradicionais não se adéquam à educação ambiental, e que os resultados das ações de educação ambiental dificilmente têm uma relação direta com uma única atividade que possa ser avaliada de forma isolada e independente. Portanto, a avaliação desses processos não pode se restringir somente a uma perspectiva de análise, deve levar em conta diversos aspectos da realidade e recorrer a diversas dimensões do conhecimento.

Em geral, há uma complexidade em torno da avaliação de programas de educação ambiental, onde a preocupação com a excelência do processo avaliativo pode torná-lo demasiadamente complexo e comprometer a sua operacionalidade, perdendo o foco da gestão e melhoria do programa. Por outro lado, em algumas situações, o entendimento do insucesso de um programa de educação ambiental demanda uma análise detalhada de várias questões (LOPES et al., 2011)

Lopes et al. (2011), investigando o motivo que tem levado muitas iniciativas de cunho ambiental fracassarem em uma escola rural, analisou várias questões, como: a opinião das(os) estudantes quanto ao local de residência e estudo, as práticas de lazer, quais os problemas socioambientais perceptíveis, entre outras, concluiu que, devido às diversas pressões e preconceitos pelos quais o meio rural já passou, as(os) estudantes apresentam um fraco vínculo com as questões ambientais e com o modo de vida rural.

Diferentemente de Lopes et al. (2011), o trabalho de Corrêa et al. (2012) assemelhou-se ao presente estudo no aspecto em que trabalhou com um público menos resistente a mudança de comportamento (jovens universitários), facilitando o desenvolvimento do programa e a obtenção de resultados favoráveis. Os autores aplicaram as ferramentas de educação ambiental no sentido de potencializar a participação de indivíduos em um programa de coleta seletiva de lixo. O programa de educação ambiental foi estruturado conforme o ciclo PDCA (planejar, implantar, monitorar e atuar), apresentando um claro propósito de gestão, onde o monitoramento foi a partir de resultados quantitativos do volume de lixo separado em um dado intervalo de tempo.

Por meio de uma ampla revisão bibliográfica, Santos e Da Silva (2011) analisaram as causas das experiências em educação ambiental não alcançarem os seus objetivos. Um ponto importante destacado pelos autores foi a falta de organização e métodos científicos na aplicação de pesquisas em educação ambiental. Nesse aspecto se destaca o trabalho de Rêgo (2011) em um trabalho específico para o público adulto, destacando que embora a 
educação ambiental tenha uma considerável bagagem de conhecimento acumulado, ainda não tem um direcionamento orientado de forma correta para atuar ativamente a favor de si e do meio a que pertence. Portanto, além de especialistas em educação e em meio ambiente, o sucesso de um programa de educação ambiental depende da capacidade de gestão de um processo multidisciplinar e complexo como bem colocado por Silva e Leite (2008: p. 378),

Para a realização da educação ambiental é necessário que o educador verifique a percepção dos atores sociais, promova um diagnóstico do meio em estudo, e trace estratégias que abranjam toda a comunidade participante na busca de soluções para os problemas.

\section{Conclusões}

A estruturação do programa de educação ambiental foi bem simples e, embora o assunto tratado seja complexo e multidisciplinar, não demandou vultosos recursos ou mão de obra extremamente especializada. Por ser um tema, em geral, bem aceito por todos, teve sua aplicação facilitada pela boa vontade das pessoas na "abertura de portas", na participação e no patrocínio de equipamentos. Naturalmente, deve ser acrescentado que a realização de qualquer pesquisa dentro de um campus universitário, principalmente, uma pesquisa relacionada ao tema "educação" é facilitada.

Apesar de modesto e rápido, o programa de educação ambiental alcançou resultados contundentes na mudança de atitude dos envolvidos. A redução das bitucas descartadas no chão, pelo menos no curto prazo, foi incontestável. Nesse aspecto, destaca-se que o público trabalhado possui um conhecimento ambiental acima da média e as informações abordadas são de simples entendimento, pois, ao contrário de outros lixos, os resíduos gerados pelas bitucas fazem parte do dia a dia das pessoas. Portanto, uma simples exposição do tema foi suficiente para as pessoas mudarem de comportamento.

\section{Referências}

ADAMS, B.G. Educação Ambiental e interdisciplinaridade no contexto educacional: algumas considerações. Rev. Educ. Ambient. em Ação, v. 6, n. 19, p. 1-3, 2006.

AFONSO, A.C.B. O consumidor verde: perfil do comportamento de compra. Lisboa, 2010. 117 f. Dissertação (Mestrado em Marketing) - Universidade Técnica de Lisboa, Instituto Superior de Economia e Gestão.

AZEVEDO, A. A. Avaliando um programa de educação ambiental em uma empresa do setor siderúrgico: características e possibilidades desse instrumento de gestão. 122 f. Dissertação (Mestrado em Economia), Departamento de Economia, Universidade de Brasília, Brasília, 2003. 
BUTZKE, I.C.; PEREIRA, G.R.; NOEBAUER, D. Sugestão de indicadores para avaliação do desempenho das atividades educativas do sistema de gestão ambiental - SGA da universidade Regional de Blumenau - FURB. Revista Educação: Teoria e Prática, v. 9, n.16, p. 1-13, 2001.

CHAN, R.; LAU, L. Antecedents of green purchases: a survey in China. Journal of Consumer Marketing, v. 17, n. 4, p. 338-357, 2000.

CHOU, J.; ROTH, R.E. Exploring the Underlyng Constructs of Basic Concepts in Environmental Education. Journal of Environmental Education, v. 26, n.2, p. 36 - 43, 1995.

CORRÊA, E.K.; AVANCINI, A.R.; MONCKS, R.B.; PAZ, M.F.; CORRÊA, L.B. Utilização de ferramentas de educação ambiental na implantação do programa de coleta seletiva no centro de engenharia da Universidade Federal de Pelotas. Revista Eletrônica do Mestrado em Educação Ambiental, v. 29, p. 1 - 16, 2012.

DEPRESBITERIS, L. Avaliação da Aprendizagem na Educação Ambiental: uma relação muito delicada. In: SATO, M; SANTOS, J. (Org.). A Contribuição da Educação Ambiental à Esperança de Pandora. São Carlos: RIMA, p. 531$557,2001$.

DIAS, R. Marketing ambiental: ética, responsabilidade social e competitividade nos negócios. São Paulo: Atlas, 2009. 200 p.

HOFFMANN, R. Estatística para economistas. 4. ed., São Paulo, Pioneira Thomson Learning, 2006.

INCA. Falando sobre tabagismo. Rio de Janeiro: Ministério da Saúde, 1996. Disponível em: <http://www1.inca.gov.br/inca/Arquivos/t Tabagismo.pdf>. Acesso em 10/02/2013.

INCA. Tabagismo: um grave problema de saúde pública. Instituto Nacional de Câncer 2007. Disponível em: <http://www1.inca.gov.br/inca/Arquivos/t Tabagismo.pdf>. Acesso em: 31 maio de 2013.

LAYRARGUES, P.P. Educação para a gestão ambiental: a cidadania no enfrentamento político dos conflitos socioambientais. Sociedade e Meio Ambiente: a educação ambiental em debate, v.1, p. 87-155, 2000.

LAYRARGUES, P. P. A natureza da ideologia e a ideologia da natureza: elementos para uma sociologia da educação ambiental. Tese (Doutorado em Ciências Sociais) Universidade de Campinas, Campinas, 2003. Disponível em: $<$ http://libdigi.unicamp.br/document/?code=vtls000293110 $>$. Acesso em $16 / 05 / 2013$.

LOPES, P.R.; SOUZA, I.F.; LEME. M.; BRANDÃO, J.A.V.; COSTA, R.M.G.F.; FIGUEIREDO, R.A. Diagnóstico socioambiental: o meio ambiente percebido por estudantes de uma escola rural de Araras (SP). Pesquisa em Educação Ambiental, v. 6, n. 1, p. 139 - 155, 2011. 
LOUREIRO, C.F.B. Trajetória e fundamentos da Educação Ambiental. São Paulo: Cortez. 2004.

MATTOS, L.M.A.; LOUREIRO, C.F.B. Avaliação em educação ambiental: estudo de caso de um projeto em contexto de licenciamento. Pesquisa em Educação Ambiental, v. 6, n. 2, p. 33-43, 2011.

PEDRINI, A.G.; BROTTO, D.S.; MESSAS, T.P. Avaliação de aproveitamento no I curso de atualização em EA para o turismo marinho e costeiro (I CEAM). Revista Eletrônica do Mestrado em Educação Ambiental, v. 28, p. 133-147, 2012.

PESTANA, M.H; GAGEIRO, J.N. Análise de Sados para Ciências Sociais: A Complementaridade do SPSS. 4. ed. Lisboa: Edições Silabo, 2005.

RÊGO, A.C.F. Educação ambiental para adultos. Ambiente \& Educação, v. 16, n. 2, p. 123-133, 2011.

SANTOS, N.L.; SILVA, M.M.P. Por que educação ambiental não tem alcançado mudanças significativas na sociedade contemporânea? Uma análise de artigos publicados em eventos científicos no Brasil de 2005 a 2010. Revista Eletrônica do Mestrado em Educação Ambiental, v. 7, p. 122-138, 2011.

SILVA, M.M.P.; LEITE, V.D. Estratégias para realização de Educação Ambiental em escolas do ensino fundamental. Revista Eletrônica do Mestrado em Educação Ambiental, v. 20, p. 372-392, 2008.

SOARES, F.J. Avaliando a dimensão ambiental na educação: um estudo com alunos do ensino fundamental de Ivoti, RS. 183 f. Dissertação (Mestrado em Ensino de Ciências e Matemática), Universidade Luterana do Brasil, Canoas, 2005.

STRAUGHAN, R.D.; ROBERTS, J. Environmental segmentation alternatives: a look at green consumer behavior in the new millennium. The Journal of Consumer Marketing, v. 16, n. 6, p. 558, 1999.

TABANEZ, M.F.; PADUA, S.M.; SOUZA, M.G.; CARDOSO, M.M.; GARRIDO, L.M.A.G. Avaliação de trilhas interpretativas para Educação Ambiental. In: PADUA, S.M.; TABANEZ, M.F. (Org.) Educação Ambiental: caminhos trilhados no Brasil. Brasília: IPÊ, 1997, p. 89-102.

TOMAZELLO, M.G.C.; FERREIRA, T.R. C. Educação Ambiental: que critérios adotar para avaliar a adequação pedagoga em seus projetos? Ciência \& Educação, v. 7, n. 2, p. 199-207, 2001.

TRAJBER, R.; COSTA, L.B. (Org.) Avaliando a educação ambiental no Brasil: materiais audiovisuais. São Paulo: Peirópolis/Instituto Ecoar para a Cidadania, 2001.

VIEIRA, V.; DIAS, M.; BIANCONI, M. L. Avaliação de aulas em espaços não formais. Anais do ENCONTRO REGIONAL DE ENSINO DE BIOLOGIA, 2., p. 261-264, 2003. 